\title{
Laboratory Study of Conductive Properties of Contaminated Riverbed Sands in Ado-Odo Ota Local Government Area of Ogun State, Nigeria
}

\author{
Olukayode D. Akinyemi ${ }^{1}$, Jamiu A. Rabiu ${ }^{1}$, V. C. Ozebo ${ }^{1} \&$ O. A. Idowu ${ }^{2}$ \\ ${ }^{1}$ Department of Physics, University of Agriculture, Abeokuta, Ogun State, Nigeria \\ ${ }^{2}$ Department of Water Resources Management and Agrometeorology, University of Agriculture, Abeokuta, \\ Ogun State, Nigeria \\ Correspondence: Jamiu A. Rabiu, Department of Physics, University of Agriculture, Abeokuta, Ogun State, \\ Nigeria. E-mail: jamoary@yahoo.com
}

Received: January 29, 2012 Accepted: February 27, 2012 Online Published: June 19, 2012

doi:10.5539/esr.v1n2p152 URL: http://dx.doi.org/10.5539/esr.v1n2p152

\begin{abstract}
As industrial activities increase, the risk of contamination of rivers in Ado-Odo Ota Local Government Area of Ogun State in Nigeria is becoming higher. In this study, riverbed sands were collected from five major rivers in Ado-Odo Ota Local Government Area, and conductivity properties were determined after the samples have been treated with varying concentration of petrol, engine oil, diesel, caustic soda and $\mathrm{H}_{2} \mathrm{SO}_{4} . \mathrm{HANNAN}$ Electrical Conductivity Meter, KD2 Thermal Conductivity Meter and Constant Head Method were used to determine the electrical, thermal and hydraulic conductivities respectively. After treatment of the samples with different concentration of the contaminants, it was found that thermal, electrical and hydraulic conductivities of the samples were largely proportional to contaminants concentration in all the samples in general. However, with increase in concentration of caustic soda and $\mathrm{H}_{2} \mathrm{SO}_{4}$, increase in electrical and thermal conductivities of samples were observed, while increase in the concentration of other contaminants decreased the hydraulic conductivity of the samples.
\end{abstract}

Keywords: riverbed sands, thermal conductivity, electrical conductivity, hydraulic conductivity, contaminants concentration

\section{Introduction}

The disposal of wastes generated by human activities within a municipality is generally an urban problem. The recognition of the connection between human activities and pollution and need to protect human health, recreation and fisheries production led to the early development of water quality regulations and monitoring methods (Hem, 1985; Jenkins et al., 1996; USEPA, 2007). The need for socio-economic advancement has led to rapid expansion of the industrial sector in developing countries like Nigeria. These waste disposal sites are neither properly designed nor constructed. After some years a dumpsite undergoes biologically, chemically, geologically and hydro geologically mediated changes resulting in a weathering process and consequently it becomes point source for pollution of the aquiferous units close to them (Arienzo et al., 2001; Manjunatha et al., 2001; Awofolu et al., 2005; Wang \& Zhuo, 2005; Adeniyi et al ., 2008).

Thermal conductivity $(\lambda)$ is the amount of heat transferred in unit time through cross-sectional area, under a unit thermal gradient. This parameter has been investigated for a wide range of soil states, and a comprehensives review of the literature has been presented previously by Farouki (1986). The most common method for determining thermal conductivity in soil is the transient, thermal probe method (Steinmanis, 1982) which consists of a line heat source and temperature sensor. Once the probe has reached thermal equilibrium with the surrounding soil, the temperature of the heat source is rapidly increased and heat is allowed to dissipate into the surrounding soil. Thermal conductivity is a function of the rate of heat dissipation, and this can be determined from a theoretical solution of conductive heat flow from a line source through an infinite homogeneous medium (Carslaw \& Jaeger, 1959).Soil thermal properties are required in many areas of engineering, agronomy, and soil science, and in recent years considerable effort has gone into developing techniques to determine these properties. Thermal properties of soils play an important role in influencing microclimate (Ghuman \& Lal, 1985). 
Electrical conductivity on the other hand is the ability of a material to carry electric current in a metallic conductor. When a voltage is applied between two inert electrodes immersed in a solution, any ions between them will be attracted by the electrode with the opposite charge. Ions will move between electrodes and produce a current depending on the electrical resistance of the solution. Electrical conductivity plays a determinant role in two complementary aspect of the exploration of the ground surface measurements and well-logging measurement. Furthermore the concept of electrical conductivity had found a very good use in Agriculture. The conductivity meters measure the number of ions that are mobile within a liquid and this is considered the most accurate way of determining the salinity of the soil which is indicative of the ability of the soil solution to carry an electric current. When an electrical potential difference is placed across a conductor, its movable charges flow giving rise to an electric current.

Hydraulic conductivity is one of the hydraulic properties of the soil; the other involves the soil's fluid retention characteristics. These properties determine the behavior of the soil fluid within the soil system under specified conditions. More specifically, the hydraulic conductivity determines the ability of the soil fluid to flow through the soil matrix system under a specified hydraulic gradient; the soil fluid retention characteristics determine the ability of the soil system to retain the soil fluid under a specified pressure condition. Hydraulic conductivity depends on the soil grain size, the structure of the soil matrix, the type of soil fluid, and the relative amount of soil fluid (saturation) present in the soil matrix. The important properties relevant to the solid matrix of the soil include pore size distribution, pore shape, tortuosity, specific surface, and porosity. In relation to the soil fluid, the important properties include fluid density $\rho$ and fluid viscosity $\mu$. For a subsurface system saturated with the soil fluid, the hydraulic conductivity, $K$, can be expressed as follows (Bear, 1972):

$$
\mathrm{K}=\frac{\kappa \rho g}{\mu}
$$

where $k$, the intrinsic permeability of the soil, depends only on properties of the solid matrix, and g called the fluidity of the liquid, represents the properties of the percolating fluid.

Conductive properties of contaminated sands have been investigated sufficiently, but very little is found in literature on the combining electrical, thermal and hydraulic conductivities of contaminated porous media. The aim of the study therefore was to investigate the effect of contaminants on the combined conductive properties of riverbed sands.

\section{Study Area}

The study was carried out on five major rivers in Ado-Odo/Ota Local Government Area of Ogun State. Ado-odo/Ota Local Government is one of the 20 Local Government areas of Ogun State located in the West Senatorial District. Geographically, it is situated within the tropical zone lying between $60^{\circ}$ and $47^{\circ} \mathrm{N}$ of equator and $20.33^{\circ} \mathrm{E}$ and $30.18^{\circ} \mathrm{E}$ of the Greenwich's Meridian and covers a land area of 1,263 square kilometers with a Terrain of 1,010.4 sq kilometer plain land and about 252.6 square kilometers. Terrain comprises of $16 \%$ riverine and $4 \%$ hilly regions. The Local Government has an estimated population of 528,242 people (Male 262,523 \& Female 265,719) (2006 Census) with about four hundred and fifty (450) towns, villages and settlements. The map shown in Figure 1, illustrate the location of the sampling sites and the potential source of pollutants, which include agricultural wastes, industrial wastes, sewage, animal wastes, market wastes, etc. Three of the rivers (Ilogbo, Mosafejo and Ijako rivers) are located in the southern district of the area. While the remaining two (Igbogbo and Iju rivers) are located in the northern part of area. The Ijako and Ilogbo Rivers are particularly unique for several reasons. The Ijako community has undergone great economic development in recent years and is notably one of the fastest growing economically important communities in Ado-odo/ota L.G.A. which accommodates a considerable number of micro- industries (Coca-Cola Nig. Ltd, Sona Breweries plc, Universal Gas Ltd, Nigeria Foundries Ltd, 3Ace lnd. Ltd and Fine Chemicals Ltd.). The very popular market (Ilogbo market) and the timber business coupled with agricultural practices have drawn people from several cultural background in the country to make the settlement inter- tribal. This increase in anthropogenic activities surrounding the area has lead to an increase in environmental degradation. These multiple sources make it especially difficult to identify and isolate the risks associated with this contaminated water. 


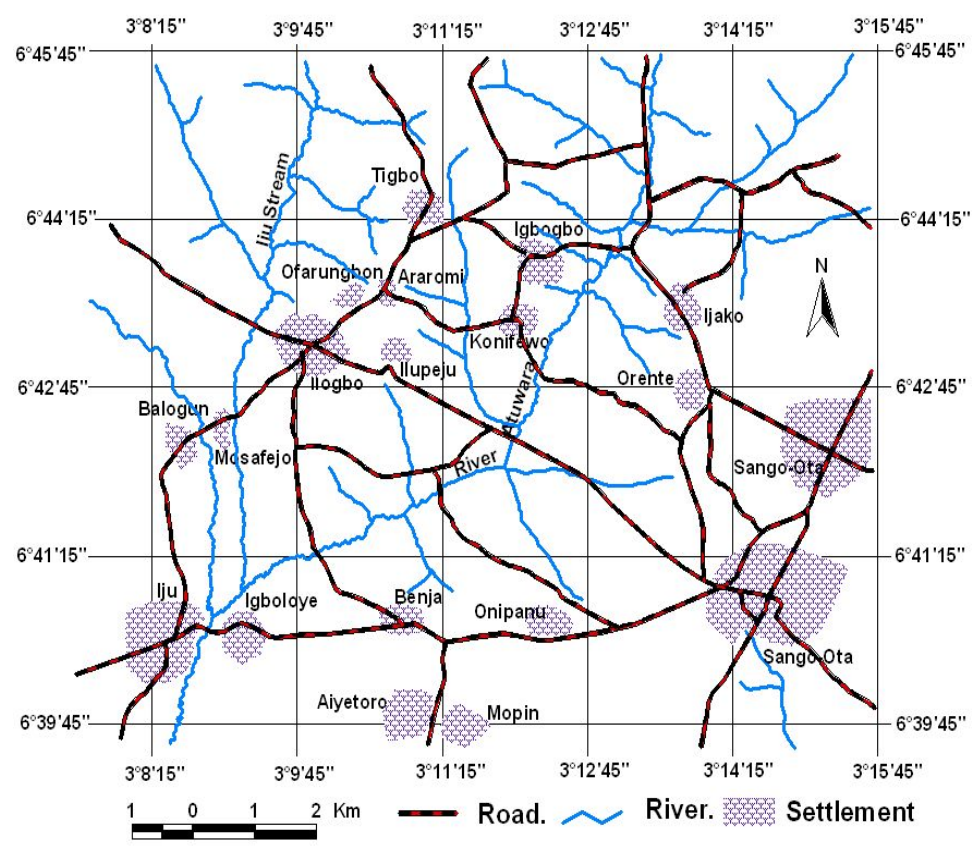

Figure 1. Map of the study area

\section{Materials and Method}

Laboratory tests were conducted to evaluate the conductivity properties at controlled room temperature $\left(25^{\circ} \mathrm{C}\right)$. Riverbed sands were collected from the five major rivers present in Ado-Odo Ota Local Government Area of Ogun state. Surface sediment samples were collected manually from the rivers' bank, transferred into plastic containers, and transported to the laboratory. Samples collected were thoroughly washed to remove any hidden contaminant, air dried and sieved to ensure uniform grain size. $1.3 \mathrm{~g} / \mathrm{cm}^{3}$ bulk density of each treated sample were moistened with uniform grain size of $0.2 \mathrm{~mm}$. Five readings of thermal conductivity and electrical conductivity were taken at different points in the cylinder in order to obtain the average values, after which hydraulic conductivity was measured using constant head method. $5 \mathrm{ml}$ of each contaminant was added and mixed thoroughly, after which thermal, electrical and hydraulic conductivities were measured. The concentration of the contaminant was increased by the same volume at each experimental set-up until $25 \mathrm{ml}$ was achieved which is the fifth concentration. For each concentration, the corresponding conductivities were recorded. Thermal properties analyzer (KD2 Decagon Devices, Inc) was used to measure the thermal properties. Measurement was carried out by inserting the needle completely into the samples. The KD2 sensor needle contains both a heating element and a thermistor.

Constant head method was used to determine the hydraulic conductivity of the samples. Eight cylindrical pipes of same diameter $(8.0 \mathrm{~cm})$ and hydraulic head $(9.0 \mathrm{~cm})$ were used in a laboratory setting to determine hydraulic conductivity, while volume rate of flow was being measured. Hydraulic conductivity was determined using Darcy's equation which can be expressed as:

$$
\mathrm{Q}=\mathrm{KA} \frac{\Delta h}{L}
$$

where $Q$ is the volumetric flow rate of water, $K$ is the hydraulic conductivity, $A$ is the cross-sectional area that the water flows through, $\Delta h$ is the change in hydraulic head and $\mathrm{L}$ is the length of the porous medium.

\subsection{Caustic Soda}

Caustic soda is the major waste product generated from (Imperial roofing sheet industry) where different types of roofing sheet are being produced. Caustic soda easily mixed with soil and end up in streams and rivers. Available commercially in various white solid forms and as a solution of various concentrations in water, it is a highly corrosive and reactive. Caustic soda, as a 50\% solution, is an odorless and colorless liquid. Upon adding it as a contaminant in the soil, increases the temperature of the soil causing an increase in conductivity of the soil. Caustic soda has a relatively very high conductivity, is soluble and very reactive with water. 


\subsection{Engine Oil}

Engine oil is a part of the family of hydrocarbons; it is being generated as a waste product from almost all industries in the study area, especially those that make use of heavy machines. During servicing and repairing, engine oil easily mixed with soil and end up in streams and rivers. Melting point and boiling point are $34.4^{\circ} \mathrm{C}$ and $360^{\circ} \mathrm{C}$ respectively, like other hydrocarbons and the fact it is insoluble, it has a rather low conductivity and its concentrations in the porous media causes a reduction in the soil even in the presence of water in the soil.

\subsection{Petrol}

Petrol is a fuel derived from petroleum crude oil and used in spark-ignited internal combustion engines. Conventional gasoline is mostly a blended mixture of more than 200 different hydrocarbon liquids ranging from those containing 4 carbon atoms to those containing 11 or 12 carbon atoms (Speight, 2008). It has an initial boiling point at temperature of about $35^{\circ} \mathrm{Cand}$ a final boiling point of about $200^{\circ} \mathrm{C}$. Octane rating, vapor pressure, sulfur content and storage stability are the properties that determine the performance of gasoline. It is important to note that petrol is covalent and made up of covalent bond.

\subsection{Diesel}

Like petrol, is also one of the major waste products generated from most industries in study area, diesel fuel contains varying amounts of various sulfur compounds which increase oil acidity. Legislation has reduced the sulfur content of highway fuel to $0.05 \%$ by weight. Off road fuel has an average of $0.29 \%$ sulfur by weight. By definition, aromatic content is characterized by the presence of the benzene family in hydrocarbon compound that occur naturally in the refining of diesel fuel. In the chemical make up of fuel, the heavier aromatic compounds toluene, xylene, and naphthalene are also present. Limiting these aromatic compounds has the effect of reducing temperature and thus NOx formation.

\subsection{Battery Acid (Electrolyte)}

An electrolyte is any substance containing free ions that make the substance electrically conductive. The most typical electrolyte generated as a waste product from (Universal Gas Ltd) situated very close to Ilogbo River is $\mathrm{H}_{2} \mathrm{SO}_{4}$. Electrolytes commonly exist as solutions of acids, bases or salts. Furthermore, some gases may act as electrolytes under conditions of high temperature or low pressure. Electrolytes solutions can also result from the dissolution of some biological (e.g., DNA. Polypeptides) and synthetic polymers (e.g., polystyrenesulfonate), termed polyelectrolytes, which contain charged functional group. Electrolyte solutions are normally formed when a salt is placed into a solvent as such as water and the individual components dissociate due to the thermodynamic interactions between solvent molecules, in a process called salvation. For example, when table salt, $\mathrm{NaCl}$, is placed in water, the salt (a solid) dissolves into its component elements, according to the dissociation reaction. If a high proportion of the solute dissociates to form free ions, the electrolytes is strong, if most of the solute does not dissociate, the electrolyte is weak the properties of electrolytes may be exploited using electrolysis to extract constituent elements and compounds contained within the solution.

\section{Results and Discussion}

Location and natural conductivity values of samples are discussed in Table 1, while Table 3 shows the decrease in Thermal, Electrical and Hydraulic conductivities of sample B as concentration of petrol, diesel and engine oil increased, while increase in conductivity properties were observed as the concentration of caustic soda and $\mathrm{H}_{2} \mathrm{SO}_{4}$ were increasing except the hydraulic conductivity which decreases as the concentration of all contaminants used increases. Table-4 shows decrease in conductivity properties of sample $\mathrm{C}$ as the concentration of contaminants such as petrol, diesel and engine oil increase. Increase in electrical and thermal conductivity was as a result of increase in concentration of caustic soda and $\mathrm{H}_{2} \mathrm{SO}_{4}$.

Table 1. samples location and natural conductivities values

\begin{tabular}{ccccc}
\hline Samples & Location & $\begin{array}{c}\text { Thermal conductivity } \\
\left(\mathrm{wm}^{-10} \mathrm{c}\right)\end{array}$ & $\begin{array}{c}\text { Electrical conductivity } \\
(\mu \mathrm{s} / \mathrm{cm})\end{array}$ & $\begin{array}{c}\text { Hydraulic conductivity } \\
(\mathrm{cm} / \mathrm{min})\end{array}$ \\
\hline A & Ilogbo River & 1.26 & 42.30 & 0.34 \\
B & Mosafejo River & 1.37 & 126 & 2.64 \\
C & Ijako River & 1.52 & 137 & 2.59 \\
D & Iju River & 3.80 & 77 & 0.54 \\
E & Igbogbo River & 2.62 & 121 & 2.10 \\
\hline
\end{tabular}




\subsection{Conductivity against Concentration}

Conductivities decreased with increase in concentration of petrol, diesel and engine oil, while increase in thermal and electrical conductivities was observed as the concentration of caustic soda and $\mathrm{H}_{2} \mathrm{SO}_{4}$ increased, except the hydraulic conductivity which decreases irrespective of contaminant used. This is due to fact that all the contaminants in porous media reduce its pore space, which resulted in flow rate reduction of water in porous media. Petrol and Diesel being a covalent hydrocarbon is a poor conductor of electrical current and heat. On the other hand, electrical and hydraulic conductivities increased with increase in concentration of Caustic Sodas and $\mathrm{H}_{2} \mathrm{SO}_{4}$ as shown in Table 2 for sample A. Caustic soda used in this study consist of $\mathrm{Na}$, O, and $\mathrm{H}$. Sodium hydroxide is a caustic compound which attacks organic matter. Upon adding it as a contaminant in the soil, it increases the temperature of the soil, causing an increase in conductivity of the soil. Caustic soda has a relatively very high conductivity, soluble and very reactive with water which has resulted in the observed conductivity trend.

Table 2. Values of thermal, electrical and hydraulic conductivity Vs Concentration of 5 contaminants for sample A

\begin{tabular}{|c|c|c|c|}
\hline $\begin{array}{l}\text { Concentration of } \\
\text { contaminant in }(\mathrm{ml})\end{array}$ & $\begin{array}{l}\text { Thermal conductivity of } \\
\text { sample } \mathrm{A}\left(\mathrm{Wm}^{-10} \mathrm{C}\right)\end{array}$ & $\begin{array}{c}\text { Electrical conductivity of } \\
\text { sample } \mathrm{A}(\mu \mathrm{s} / \mathrm{cm})\end{array}$ & $\begin{array}{l}\text { Hydraulic conductivity of } \\
\text { sample A }(\mathrm{cm} / \mathrm{min})\end{array}$ \\
\hline \multicolumn{4}{|c|}{ Petrol $(\mathrm{ml})$} \\
\hline 5 & 2.81 & 148.0 & 0.51 \\
\hline 10 & 2.42 & 135.0 & 0.42 \\
\hline 15 & 1.94 & 128.0 & 0.36 \\
\hline 20 & 1.52 & 100.0 & 0.30 \\
\hline 25 & 1.02 & 82.0 & 0.28 \\
\hline \multicolumn{4}{|c|}{ Diesel (ml) } \\
\hline 5 & 2.50 & 70.0 & 0.48 \\
\hline 10 & 2.15 & 58.12 & 0.42 \\
\hline 15 & 1.95 & 46.52 & 0.37 \\
\hline 20 & 1.48 & 40.0 & 0.30 \\
\hline 25 & 1.05 & 35.55 & 0.25 \\
\hline \multicolumn{4}{|c|}{ Engine oil (ml) } \\
\hline 5 & 1.73 & 68.0 & 0.42 \\
\hline 10 & 1.46 & 55.0 & 0.38 \\
\hline 15 & 1.25 & 42.32 & 0.33 \\
\hline 20 & 1.21 & 37.0 & 0.26 \\
\hline 25 & 1.12 & 30.0 & 0.20 \\
\hline \multicolumn{4}{|c|}{$\mathrm{H}_{2} \mathrm{SO}_{4}(\mathrm{ml})$} \\
\hline 5 & 1.80 & 100.0 & 0.67 \\
\hline 10 & 2.05 & 125.0 & 0.88 \\
\hline 15 & 2.75 & 154.0 & 1.05 \\
\hline 20 & 3.12 & 177.0 & 1.30 \\
\hline 25 & 3.82 & 190.0 & 1.75 \\
\hline \multicolumn{4}{|c|}{ Caustic soda (ml) } \\
\hline 5 & 1.25 & 130.0 & 2.01 \\
\hline 10 & 1.52 & 140.0 & 1.92 \\
\hline 15 & 1.80 & 155.0 & 1.65 \\
\hline 20 & 2.05 & 167.05 & 1.41 \\
\hline 25 & 2.30 & 175.01 & 1.20 \\
\hline
\end{tabular}




\subsection{Effect of Contaminants Concentration on Thermal Conductivity}

Tables 2-4 show the thermal, electrical and hydraulic conductivity of treated samples with various concentrations of contaminants. From the data obtained, electrical conductivity has the highest values while hydraulic conductivity has the lowest values for various concentrations of the contaminants. Figure 2 shows the decrease in thermal conductivity of sample A as the concentration of petrol, diesel and engine oil increased. And increase in thermal conductivity was observed as the concentration of caustic soda and $\mathrm{H}_{2} \mathrm{SO}_{4}$ increased. In the same way Figure 3 shows the decrease in thermal conductivity of sample B, as the concentration of petrol, diesel and engine oil increased. But thermal conductivity of sample B increased as the concentration of caustic soda and $\mathrm{H}_{2} \mathrm{SO}_{4}$ increased. Figures 4,5 and 6 also show the decrease in thermal conductivity of sample C, D and E respectively as the concentration of petrol, diesel and engine oil increased, while thermal conductivity increased with increase in caustic soda and $\mathrm{H}_{2} \mathrm{SO}_{4}$, hydraulic conductivity of all the samples decreased as the concentration of all contaminants increased.

Table 3. Values of thermal, electrical and hydraulic conductivity Vs Concentration of 5 contaminants for sample B

\begin{tabular}{|c|c|c|c|}
\hline $\begin{array}{l}\text { Concentration of } \\
\text { contaminant in }(\mathrm{ml})\end{array}$ & $\begin{array}{l}\text { Thermal conductivity of } \\
\text { sample } \mathrm{B}\left(\mathrm{Wm}^{-10} \mathrm{C}\right)\end{array}$ & $\begin{array}{c}\text { Electrical conductivity of } \\
\text { sample } \mathrm{B}(\mu \mathrm{s} / \mathrm{cm})\end{array}$ & $\begin{array}{c}\text { Hydraulic conductivity of } \\
\text { sample } \mathrm{B}(\mathrm{cm} / \mathrm{min})\end{array}$ \\
\hline \multicolumn{4}{|c|}{ Petrol $(\mathrm{ml})$} \\
\hline 5 & 3.0 & 150 & 0.81 \\
\hline 10 & 2.75 & 142 & 0.75 \\
\hline 15 & 2.45 & 135 & 0.67 \\
\hline 20 & 2.20 & 128 & 0.59 \\
\hline 25 & 1.0 & 105 & 0.50 \\
\hline \multicolumn{4}{|c|}{ Diesel (ml) } \\
\hline 5 & 2.85 & 80.0 & 0.58 \\
\hline 10 & 2.50 & 68.05 & 0.50 \\
\hline 15 & 2.20 & 58.15 & 0.42 \\
\hline 20 & 1.87 & 50.0 & 0.35 \\
\hline 25 & 1.28 & 42.0 & 0.20 \\
\hline \multicolumn{4}{|c|}{ Engine oil (ml) } \\
\hline 5 & 1.88 & 75.0 & 0.60 \\
\hline 10 & 1.53 & 62.50 & 0.51 \\
\hline 15 & 1.47 & 51.0 & 0.42 \\
\hline 20 & 1.28 & 42.05 & 0.35 \\
\hline 25 & 1.10 & 30.0 & 0.21 \\
\hline \multicolumn{4}{|c|}{$\mathrm{H}_{2} \mathrm{SO}_{4}(\mathrm{ml})$} \\
\hline 5 & 1.72 & 100.0 & 1.70 \\
\hline 10 & 2.08 & 129.0 & 1.34 \\
\hline 15 & 2.42 & 158.0 & 1.10 \\
\hline 20 & 3.05 & 168.0 & 0.88 \\
\hline 25 & 3.19 & 188.0 & 0.68 \\
\hline \multicolumn{4}{|c|}{ Caustic soda (ml) } \\
\hline 5 & 1.35 & 125.0 & 2.65 \\
\hline 10 & 1.55 & 133.0 & 2.43 \\
\hline 15 & 1.78 & 149.0 & 2.20 \\
\hline 20 & 1.95 & 155.0 & 2.00 \\
\hline 25 & 2.15 & 165.0 & 1.75 \\
\hline
\end{tabular}




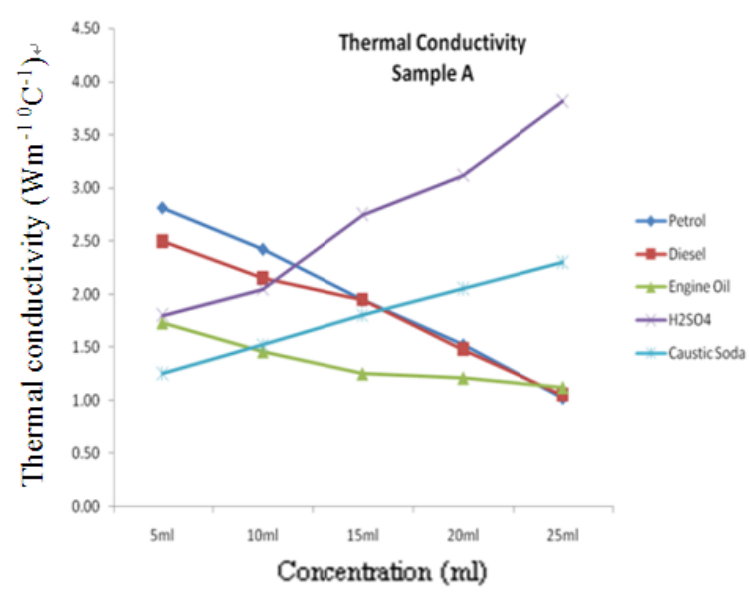

Figure 2. Effect of concentration of contaminants on thermal conductivity of sample A

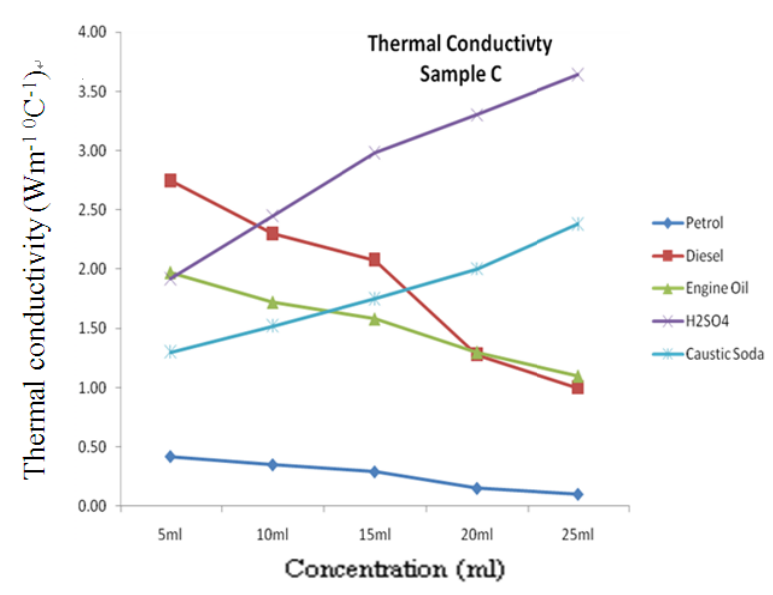

Figure 4. Effect of concentration of contaminants on thermal conductivity of sample $\mathrm{C}$

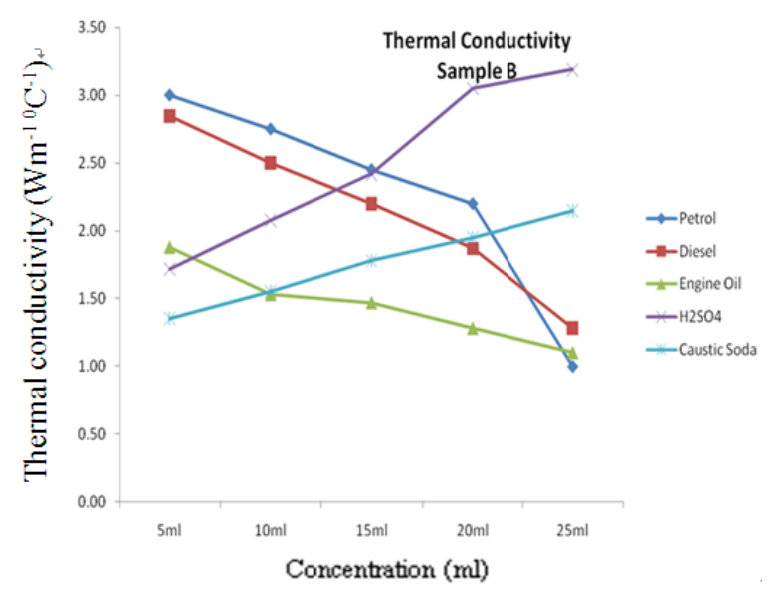

Figure 3. Effect of concentration of contaminants on thermal conductivity of sample B

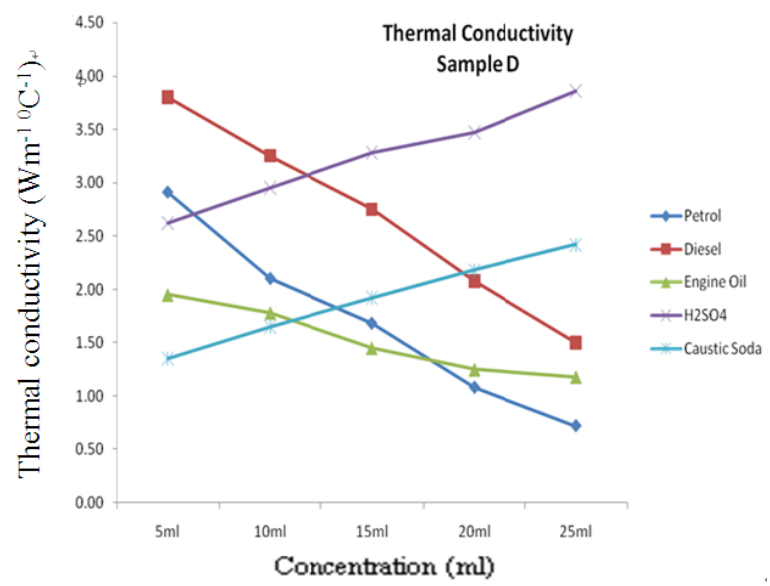

Figure 5. Effect of concentration of contaminants on thermal conductivity of sample D

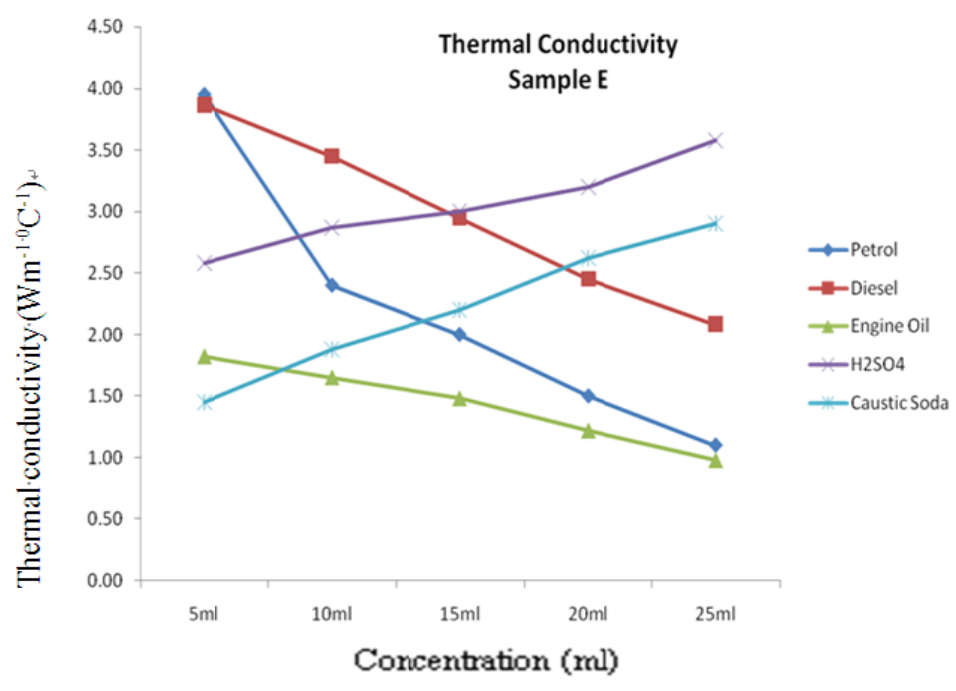

Figure 6. Effect of concentration of contaminants on thermal conductivity of sample E 


\subsection{Effect of Contaminants Concentration on Electrical Conductivity}

Electrical conductivity of samples were determined by varying the concentration of contaminants. From the data obtained it can be seen that electrical conductivity has the highest values and the hydraulic conductivity has the lowest values for various concentration of the contaminants. Figures 7 and 8 show the decrease in electrical conductivity of samples A and B as the concentration of contaminants (Petrol, Diesel and Engine oil) increased, increase in electrical conductivity as the concentration of caustic soda and $\mathrm{H}_{2} \mathrm{SO}_{4}$ increased while Figures 9, 10 and 11 show the decrease in electrical conductivity of samples C, D and E respectively as concentration of Petrol, Diesel and Engine oil increased. However electrical conductivity of samples increased as the concentration of caustic soda and $\mathrm{H}_{2} \mathrm{SO}_{4}$ increased.

Electrical Conductivty Sample A

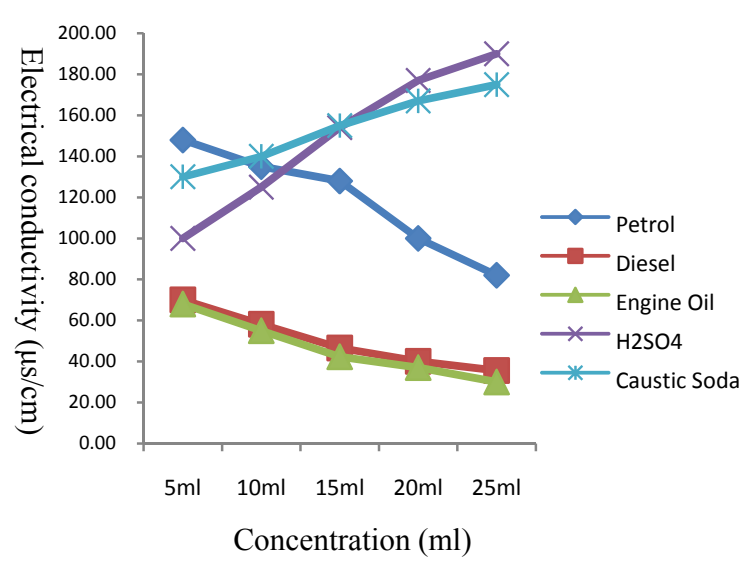

Figure 7. Effect of concentration of contaminants on electrical conductivity of sample A

\section{Electrical Conductivity Sample C}

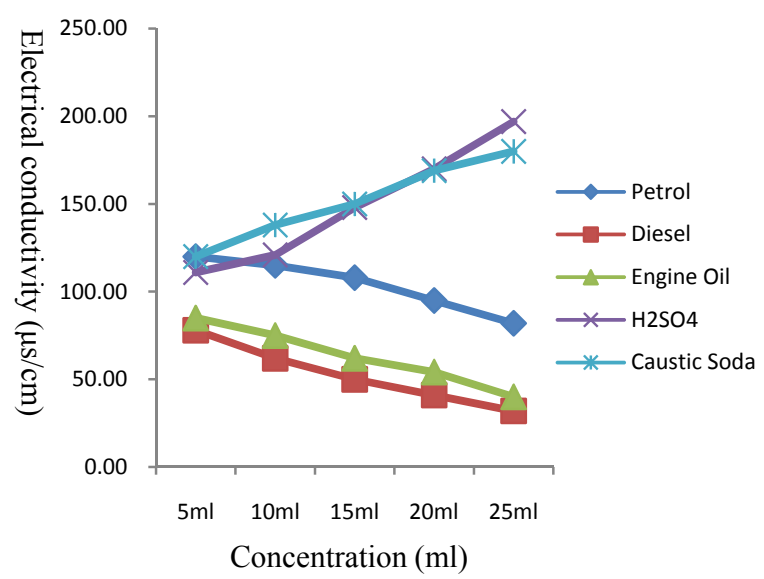

Figure 9. Effect of concentration of contaminants on electrical conductivity of sample C

\section{Electrical Conductivity Sample B}

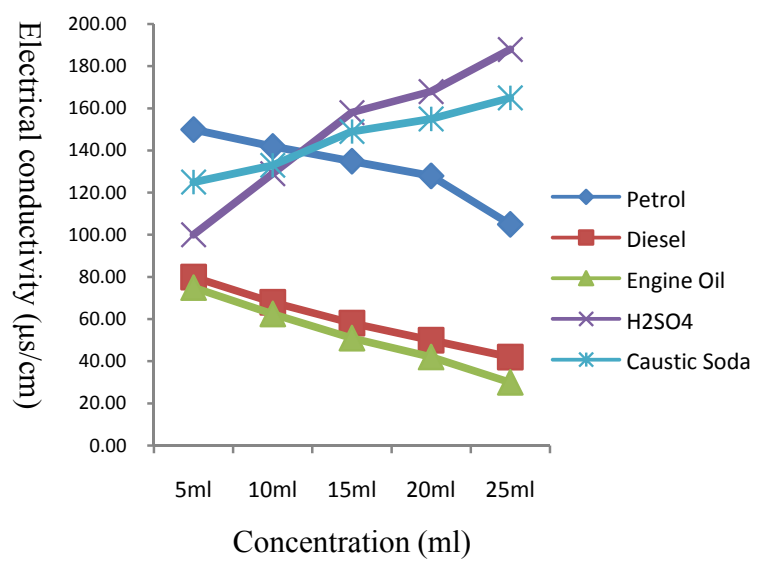

Figure 8. Effect of concentration of contaminants on electrical conductivity of sample B

\section{Electrical Conductivity Sample D}

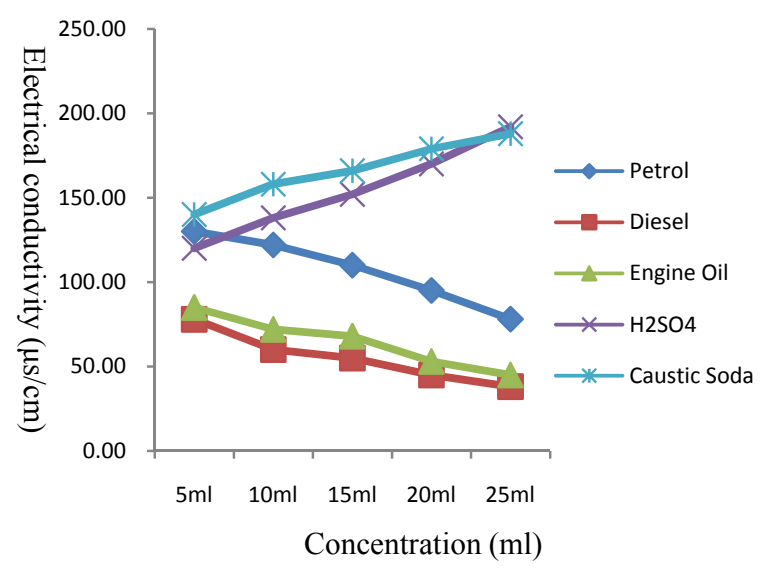

Figure 10. Effect of concentration of contaminants on electrical conductivity of sample D 


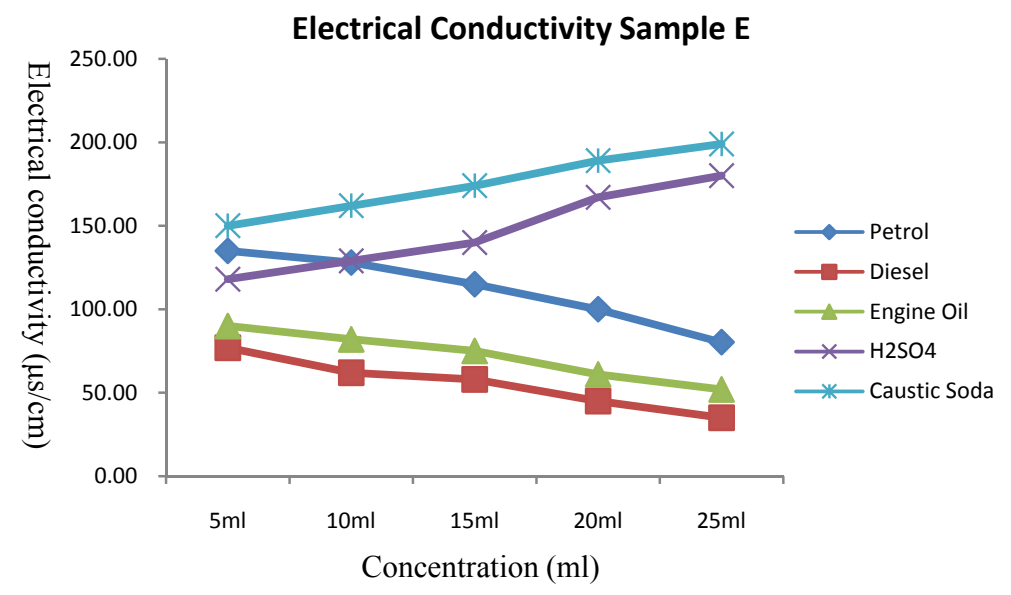

Figure 11. Effect of concentration of contaminants on electrical conductivity of sample $\mathrm{E}$

\subsection{Effect of Contaminants Concentration on Hydraulic Conductivity}

Hydraulic conductivity of samples was determined by varying the concentration of contaminants. From the data obtained in Tables 2-4, hydraulic conductivity was plotted against the concentration of the contaminants. Figures 13, 14 and 15 show the decrease in hydraulic conductivity of samples B, C and D respectively as the concentration of all the contaminants used increased. It is clearly seen from the graphs that hydraulic conductivity of all the samples decreased with increase in the concentration of Petrol, Diesel, Engine oil and Caustic Soda. Although decrease rate of conductivity differs in different soils, hydraulic conductivity increased with increase in concentration of $\mathrm{H}_{2} \mathrm{SO}_{4}$ for sample A only, because sample A is the most porous sample.

Table 4. Values of thermal, electrical and hydraulic conductivity Vs Concentration of 5 contaminants for sample C

\begin{tabular}{|c|c|c|c|}
\hline $\begin{array}{c}\text { Concentration of } \\
\text { contaminant in }(\mathrm{ml})\end{array}$ & $\begin{array}{l}\text { Thermal conductivity of } \\
\text { sample } \mathrm{C}\left(\mathrm{Wm}^{-10} \mathrm{C}\right)\end{array}$ & $\begin{array}{c}\text { Electrical conductivity of } \\
\text { sample } \mathrm{C}(\mu \mathrm{s} / \mathrm{cm})\end{array}$ & $\begin{array}{c}\text { Hydraulic conductivity of } \\
\text { sample } \mathrm{C}(\mathrm{cm} / \mathrm{min})\end{array}$ \\
\hline \multicolumn{4}{|c|}{ Petrol $(\mathrm{ml})$} \\
\hline 5 & 0.42 & 120.0 & 2.50 \\
\hline 10 & 0.35 & 115.0 & 2.10 \\
\hline 15 & 0.29 & 108.0 & 1.49 \\
\hline 20 & 0.15 & 95.0 & 1.40 \\
\hline 25 & 0.10 & 82.0 & 1.08 \\
\hline \multicolumn{4}{|c|}{ Caustic soda (ml) } \\
\hline 5 & 1.30 & 120.0 & 2.85 \\
\hline 10 & 1.52 & 138.0 & 2.60 \\
\hline 15 & 1.75 & 150.0 & 2.39 \\
\hline 20 & 2.00 & 169.0 & 2.28 \\
\hline 25 & 2.38 & 180.0 & 2.10 \\
\hline \multicolumn{4}{|c|}{ Diesel (ml) } \\
\hline 5 & 2.75 & 78.0 & 0.60 \\
\hline 10 & 2.30 & 62.0 & 0.58 \\
\hline 15 & 2.08 & 50.0 & 0.45 \\
\hline 20 & 1.28 & 41.0 & 0.40 \\
\hline 25 & 1.0 & 32.0 & 0.32 \\
\hline \multicolumn{4}{|c|}{ Engine oil (ml) } \\
\hline 5 & 1.97 & 85.0 & 0.77 \\
\hline 10 & 1.72 & 75.0 & 0.62 \\
\hline 15 & 1.58 & 62.05 & 0.51 \\
\hline 20 & 1.30 & 54.15 & 0.43 \\
\hline
\end{tabular}




\begin{tabular}{cccc}
\hline 25 & 1.10 & 40.0 & 0.30 \\
\hline 5 & & $\mathrm{H}_{2} \mathrm{~S}_{4}(\mathrm{ml})$ & \\
10 & 1.92 & 111.0 & 1.80 \\
15 & 2.45 & 121.0 & 1.48 \\
20 & 2.98 & 148.0 & 1.15 \\
25 & 3.30 & 170.0 & 0.85 \\
\hline
\end{tabular}

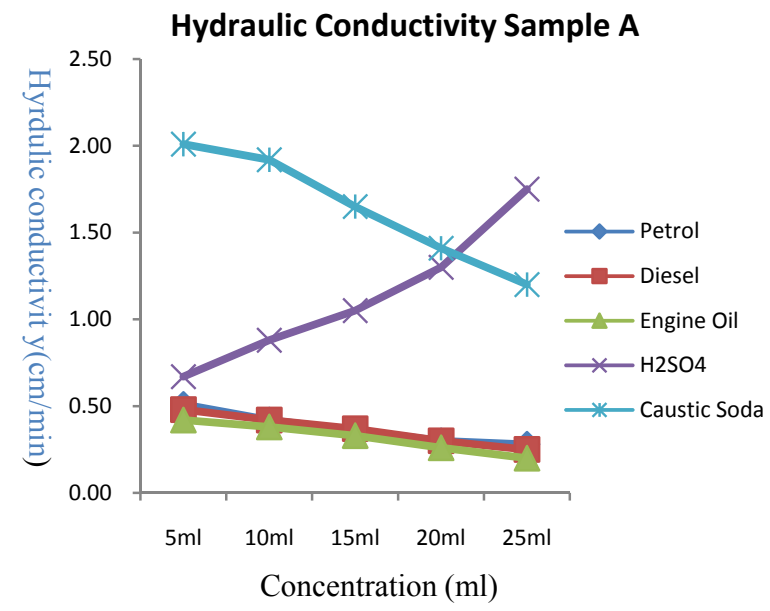

Figure 12. Effect of concentration of contaminants on hydraulic conductivity of sample A

\section{Hydraulic Conductivity Sample C}

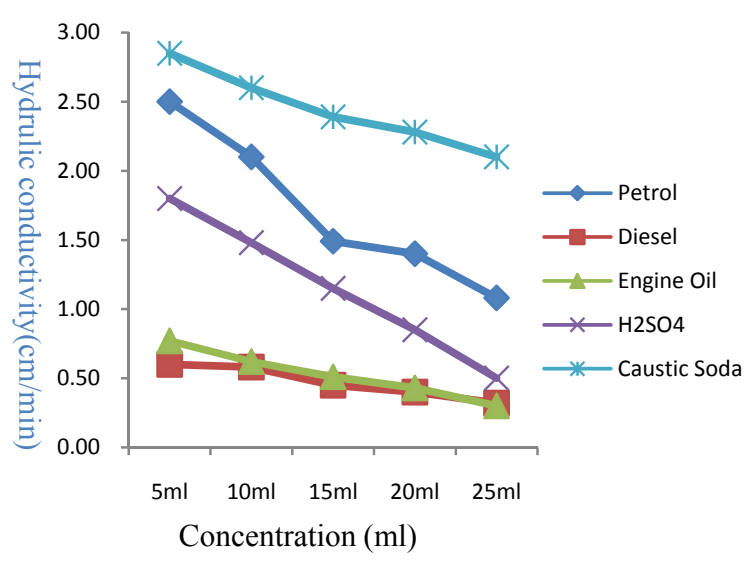

Figure 14. Effect of concentration of contaminants on hydraulic conductivity of sample $\mathrm{C}$
Hydraulic Conductivity Sample B

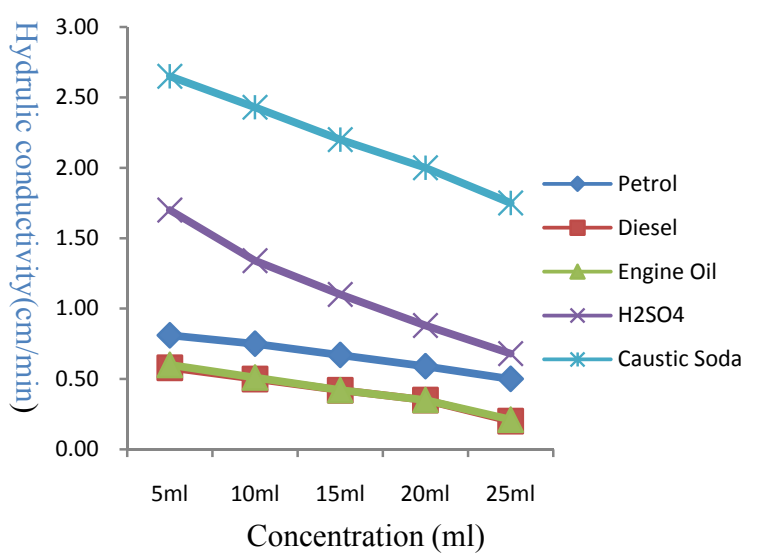

Figure 13. Effect of concentration of contaminants on hydraulic conductivity of sample B

\section{Hydraulic Conductivity Sample D}

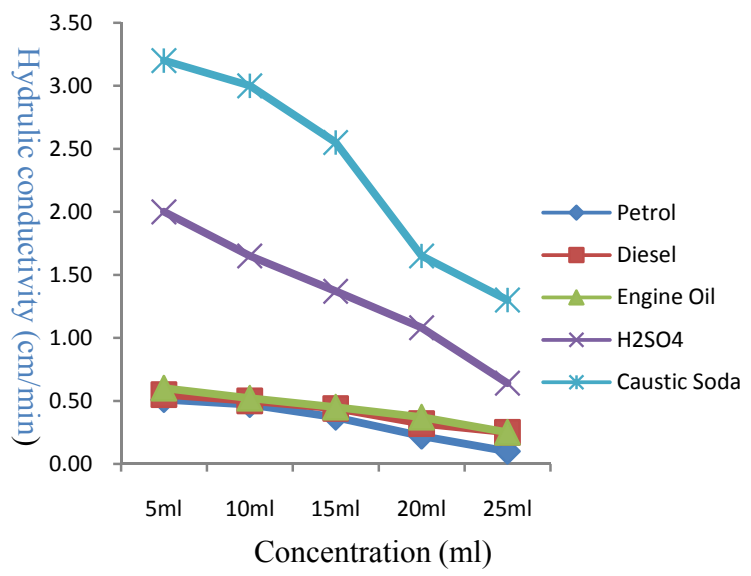

Figure 15. Effect of concentration of contaminants on hydraulic conductivity of sample D 


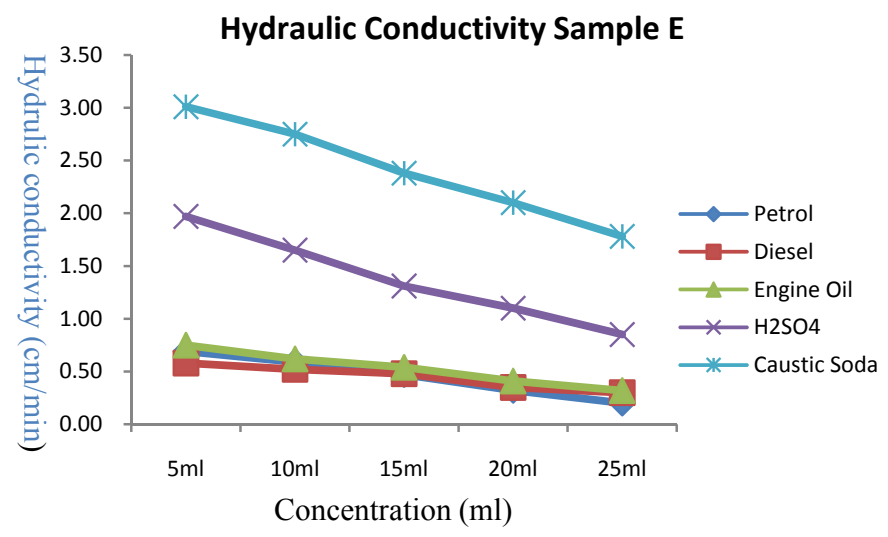

Figure 16. Effect of concentration of contaminants on hydraulic conductivity of sample E

\section{Conclusion}

General conductive properties of contaminated riverbed sands have been determined in this study to investigate variation with contaminants concentrations. Thermal, Electrical and Hydraulic conductivity varies with respect to contaminants present in porous media. Conductivity decreased with increase in the concentration of Petrol, Diesel and Engine oil. As observed in Table 4, electrical and thermal conductivities of sample $\mathrm{C}$ increased as the concentration of Caustic soda and $\mathrm{H}_{2} \mathrm{SO}_{4}$ increased. Hydraulic conductivity of sample $\mathrm{C}$ decreased as the concentration of all contaminants used in this study were increased. It was also already observed for all the samples investigated, conductive properties varied linearly with the increase in concentration. Presence of hydrocarbons in the riverbed sands reduces electrical and thermal conductivities.

Other contaminant such as Caustic Soda and Battery acid, if as a contaminant found in any porous media, increases electrical and thermal conductivity, but all contaminants investigated reduce hydraulic conductivity of porous media, due to the fact that contaminants reduce pore space, which directly reduced the rate of flow of water.

\section{References}

Adeniyi, A. A., Yusuf, O. O., \& Okedeyi, O. O. (2008). Assessment of the exposure of two fish species to metals pollution in the Ogun river catchments, Ketu, Lagos, Nigeria. Environ Monit Assess., 137(1-3), 451-458. http://dx.doi.org/10.1007/s10661-007-9780-5

Arienzo, M., Adamo, P., Bianco, M. R., \& Violante, P. (2001). Impact of land use and urban run-off on the contamination of the Samo river basin in southwestern Italy. Water Air Soil Pollut., 131(1-4), 349-366. http://dx.doi.org/10.1023/A:1011908019933

Awofolu, O. R., Du Plessis, R., \& Rampedi, I. (2007). Influence of discharged effluent on the quality of surface water utilized for agricultural purposes. Afr. J. Biotech., 6(19), 2251-2258.

Awofolu, O. R., Mbolekwa, Z., Mtshemla, V., \& Fatoki, O. S. (2005). Levels of trace metals in water and sediment from Tyume river and its effects on an irrigated farmland. Water S. Afr., 31(1), 87-94.

Carslaw, H. S., \& Jaeger, J. C. (1959). Conduction of heat in solids. Oxford: Clarendon Press. p. 510.

Cremers, A., \& Laudelout, H. (1965). Note on the 'Isoconductivity Value' of clay gels. Soil Science, 100, 298-299. http://dx.doi.org/10.1097/00010694-196510000-00012

Farouki, O. T. (1986). Thermal properties of soils. Rock and Soil Mechanics, Vol. 11, Trans Tech Publications, Clausthal-Zellerfeld, Germany. p. 1-136.

Ghauman, B. S., \& R. Lal. (1985). Thermal conductivity, thermal diffusivity, and thermal capacity of some Nigerian soils. Soil Sci., 139(1).

Hem, J. D. (1985). Water supply paper. Study and interpretation of the chemical characteristics of natural water (3rd. ed.). University Press of the Pacific. P. 2254.

Steinmanis, J. E. (1982) Thermal property measurements using a thermal probe. Underground cable thermal backfill. New York: Pergamon Press. p 72-85.

USEPA. (2007). Recent recommended water quality criteria. United States Environmental Protection Agency. 